\title{
Supraglottic Airway Devices: An Overview
}

\author{
AHMED M.S. EL NAGGAR, M.D.*; DOAA M. FARID, M.D.*; YASSER M. NASR, M.D.* and \\ EMADEDDEN N.O. ALARGA, M.Sc.** \\ The Department of Anesthesia and Surgical Intensive Care, Faculty of Medicine, Zagazig University, Egypt* and \\ Almergib University, Libya**
}

\begin{abstract}
Background: Supraglottic Airway Devices relates to a wide range of medical devices that can act as a passage way for oxygenation, ventilation and administration of anesthetic gas. In recent decades, their acceptance has gradually risen, becoming a basic instrument in contemporary anaesthesiology. Due to their simplicity, speed of insertion, and efficacy, some writers refer to them as extraglottic periglottic or supralaryngeal airways, but the word' supraglottic airways devices SADs is the most commonly used in this review. Brain's Laryngeal Mask Airway, launched in 1983, marked the start of a revolution as a new technique for airway management, eventually replacing the most commonly used tracheal intubation. SADs is employed to protect the airway in both elective as well as emergency situations. One of the first SADs to come on the market was the Laryngeal Mask Airway (LMA), invented by an anesthesiologist named Archie Brain in England. Brain was attempting to find a handsfree approach to ventilation that did not involve inserting a tube into the patient's trachea.

Aim of Work: The aim of this essay was to discuss the supraglottic Airway devices to depict their highlights and its classification to know the fundamental of its advantage and disadvantage.
\end{abstract}

Key Words: Supraglottic airway devices.

\section{Introduction}

SUPRAGLOTTIC Airway Devices (SADs) include an enormous collection of tools capable of acting as a passageway for ventilation, oxygenation and administration of anaesthetic gases [1].

One of the first SADs to come on the market was the Laryngeal Mask Airway (LMA), invented by an anesthesiologist named Archie Brain in England, brain was attempting to find a handsfree approach to ventilation that did not involve inserting a tube into the patient's trachea [2]

Correspondence to: Dr. Emadedden N.O. Alarga, E-Mail: emadnore39@gmail.com
Due to their simplicity, speed of insertion, and efficacy, supraglottic airway devices are commonly used in the pre-hospital setting. Some writers refer to them as extraglottic [3], periglottic [4] or supralaryngeal [5] airways, but the word' supraglottic airways' is the most commonly used in this review.

\section{Aim of the work:}

The aim of this essay was to discuss the supraglottic Airway devices to depict their highlights and its classification to know the fundamental of its advantage and disadvantage.

\section{Review of Literature}

\section{History of development:}

Endotracheal intubation was a very complicated operation at the end of the 19 th century, with a high failure rate which resulting in death [6].

In 1937, Leech launched the Pharyngeal Bulb Gasway Fig. (1). Instead of dipping into the trachea, this instrument would be stuck in the pharynx by anatomically shaped, becoming the first supraglottic airway device [7].

Despite the benefits of Leech's airway compared with the face mask or the ET, it was not very common used, and the uses of muscle relaxant with laryngoscope for tracheal intubation was gold standred for general anesthesia [8].

It took nearly 50 years to invent another supraglottic airway device. Archie brain argued that tracheal intubation was not optimal in gas flow as it resulted in potential damaging flow turbulences with the tube, ET inside another trachea. He designed the Laryngeal Mask Airway [9].

- Classification of supraglottic airway devices [10]: These devices can be classified according to 
generation, sealing mechanism (cuffed or cuffless) and number of lumen.

\section{1- According to generation:}

I- First generation simple airway device, low pressure pharyngeal seal, may or may not protect from aspiration, have no specific design to lessen the risk. e.g., cLMA, Flexible LMA, Cobra perilaryngeal airway. Air Q classic and self pressurized.

II- Second generation specially designed for safety, high pressure pharyngeal seal. Reduce the risk of aspiration, may be more efficacious in ventilation e.g., PLMA, supreme LMA, Laryngeal tube suction, I-gel, SLIPA, Air. Q blocker, Ambu LMA.

III- Third generation e.g.: Baska mask.

\section{2- Based on the number of lumen:}

- Single Lumen Devices: LMA-classic, LMAunique, LMA-flexible, ILMA, Ambu Laryngeal Mask, Cobra Perilaryngeal Airway (CPLA), Laryngeal Tube (LT), cuffed oropharyngeal airway, Stream Lined Liner of the Pharyngeal Airway (SLIPA), classic Air Q, slef pressurized Air Q.

- Double lumen devices: Proseal LMA, Combitube, Laryngeal Tube Suction (LTS).

- Tripple lumen devices: Elisha Airway Device (EAD).

3- According to sealing mechanism: (Cuffed and cuffless):

A- SGD with an inflatable periglottic cuff:

- ILA/airQ (Cookgas).

- LMA device family (LMA Company).

- Soft Seal Laryngeal Mask (Portex).

B- SGDs with no inflatable cuff:

- I-gel (Intersurgical).

- SLIPA (Slipa Medical).

- Baska mask.

C- SGDs with 2 inflatable cuffs:

- Laryngeal Tube family (King Systems).

- Esophageal Tracheal Combitube.

D- SGDs with single pharyngeal inflatable cuff:

- Cobra PLA family (Pulmodyne).

LMA family development:

1- LMA classic: Fig. (2):

It was the first with importance although not the first SAD. It has two elastic bands to prevent the epiglotte from blocks the flow of air, which are made up of an oval inflatable cortex intended to secure the larynx. It can be reused up to 40 times after autoclaving [11]

In comparison to ET, both inexpert and trained anestheticians increase speed and ease of cLMA placing [12]

Lower anesthetic levels are needed and the risk of sore throat is decreased [13]. However, it has reduced sealing pressures and a greater incidence of gastric insufflation [14]

\section{2- LMA Unique: Fig. (3):}

The LMA Unique is a disposable, single-use version of the LMA Classic, introduced in 1997. Instead of silicone, the mask is made of Polyvinyl Chloride (PVC). It therefore does not require sterilization, and compared to the reusable LMA Classic, has zero risk of residual contamination from prior use. This innovation came at a critical time with rising clinician concern over transmission of life-threatening prion protein diseases, such as Creutzfeld-Jakob disease, which were found to be resistant to autoclave sterilization [15]

\section{LMA classic and unique clinical evidence:}

Although the LMA classic has been used successfully in millions of pediatric patients for many years, it is known to be problematic in children weighing less than $10 \mathrm{~kg}$. Limitations include poor airway seal, mask displacement, and gastric insufflation of air [16]

The LMA unique is a disposable version of the LMA classic, and was found to be similar in performance to the LMA classic in pediatric patients. There are many case reports of successful use of both the LMA classic and LMA unique in pediatric patients with difficult airways [17].

The LMA classic is the most extensively described SADs for neonatal resuscitation in both observational and randomized controlled trials, with successful resuscitations in $95-99 \%$ of cases, decrease in the need for tracheal intubation when compared to bag mask ventilation, lower NICU admissions [18] and shorter lengths of stays when compared to face/bag mask ventilation and endotracheal tube (ETT) [19]

3- LMA flexible: Fig. (4):

Differs from the LMA-classic in that it has a flexible, wire-reinforced tube. This tube is longer and narrower than the tube on the LMA-classic. Useful for face and neck surgery providing little risk of airway displacement [20] 


\section{4- Combitube: Fig. (5):}

Combining the features of an ET and a gastric tube the device consists of two lumens: A "pharyngeal" lumen and a "tracheal" lumen separated by a partition wall, one lumen has an open distal end, similar to an ETT, and the other is closed at the distal end, with multiple ventilating eyes proximal to its inflatable cuff the combitube was designed to be inserted blindly however it can be used after esophageal or tracheal insertion the use of the combitube is not recommended for general anaesthetic procedures, being limited to emergency situations, especially out-of-hospital [21].

\section{5- Intubating LMA (Fastrach): Fig. (6):}

This is easier to implement than an endotracheal tube and subsequently enables blind intubation to be carried out with an ET in the size of 8 by itself it also enables ventillation, like other SADs [22].

\section{6- LMA-CTrach: Fig. (7):}

The LMA-CTrach is comparative in development to the LMA-Fastrach. It has two worked in fiberoptic channels, one to pass on light from and the other to pass on the picture to the watcher [23] The fiberoptic system is sealed and robust, so the LMA-CTrach can be autoclaved [24]. The screen (watcher) has controls for centering and picture alteration. The watcher is battery worked. The battery gives up to 30 minutes of ceaseless utilize and can be revived. The LMA-CTrach is accessible in sizes 3,4 , and 5 and is reusable up to 20 times [25].

\section{7- LMA proseal (PLMA): Fig. (8):}

This SAD enhances the design with a second, rear cuff, stronger airway seal, enabling a greater oropharyngeal seal pressure of $27 \mathrm{~cm}(27 \mathrm{~cm})$ of
$\mathrm{H} 2 \mathrm{O}$. It was also the first to permit access through an esophagus drain pipe through gastrointestinal tract. These enabled better efficiency and safety, reduced aspiration risk and helped to evaluate the right positioning by placing a gastric tube, so the location of the device tip can be found. In order to avoid obstruction, airways and drain tubes are attached to a rigid structure if the patient closes his teeth [26]

\section{8- LMA supreme (SLMA):}

This was a PLMA trend reinforcement cuff to avoid folding, a narrow curve to facilitate insertion and stable positioning, and it is a single-use tool. Non-inferior compared with PLMA, and superior efficiency relative to cLMA have been demonstrated through several research [27]

\section{9- I-Gel: Fig. (9):}

It is a new cuffless polymer airway of similar basic design to the PLMA gel-like instrument which, after insertion, is adapted to the anatomic surface. A canal to insert a gastric pipe is also provided. Recent studies have demonstrated that the I-gel provides a secure and reliable airway, and is easily and rapidly inserted even by novice users [28].

\section{0- Baska mask: Fig. (10):}

This is one of the most recent instruments with a radically distinct sealing system. It has a noninflatable cuff, which is continuous with the airway lumen, allowing for expansion with positive pressure ventilation while also avoiding the problems of cuff over-inflation. In a research of 150 clients, it accomplished stronger sealing (40 versus $22 \mathrm{~cm}$ $\mathrm{H}_{2} \mathrm{O}$ ) but was harder to achieve than cLMA leading to greater initiation moments [29]

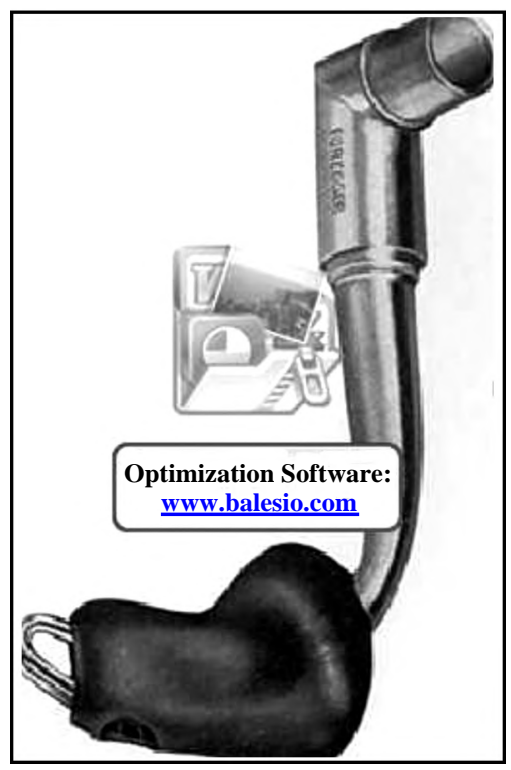

Fig. (1): Pharyngeal bulb gasway.

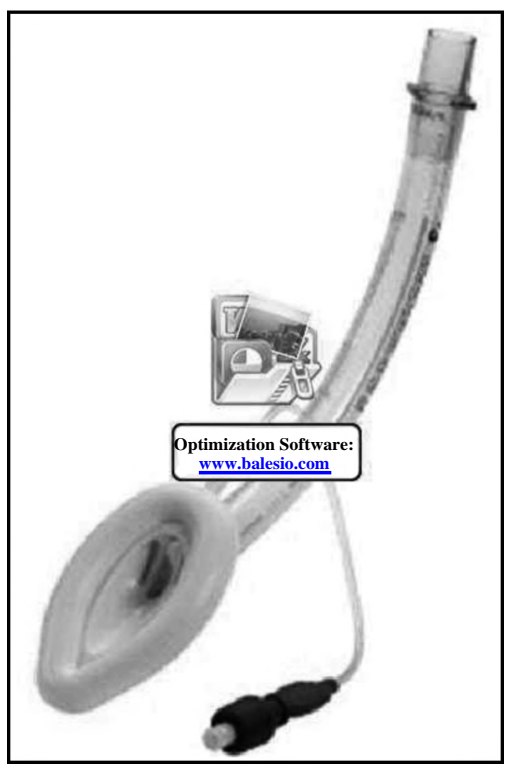

Fig. (2): Classic LMA.

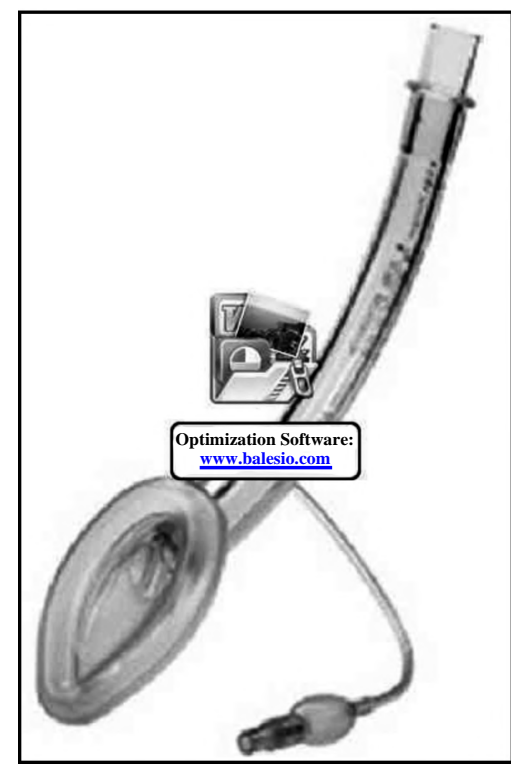

Fig. (3): LMA unique. 


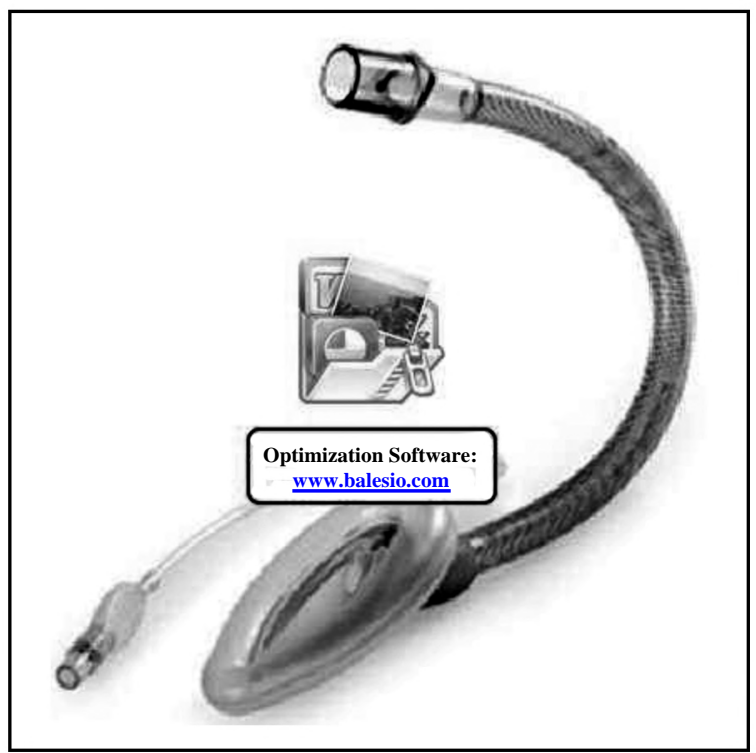

Fig. (4): Flexible LMA.

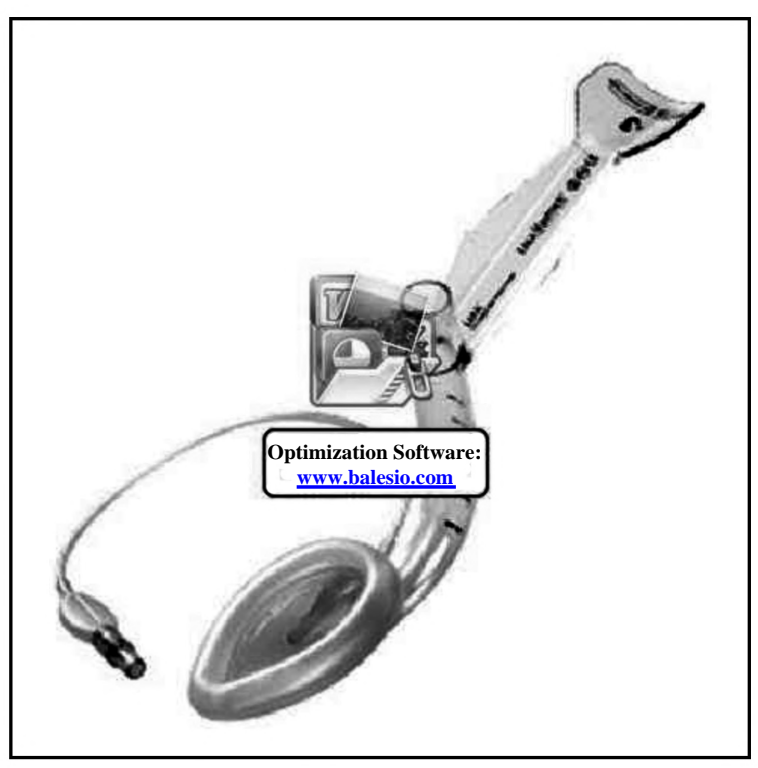

Fig. (6): Intubating LMA (Fastrach).

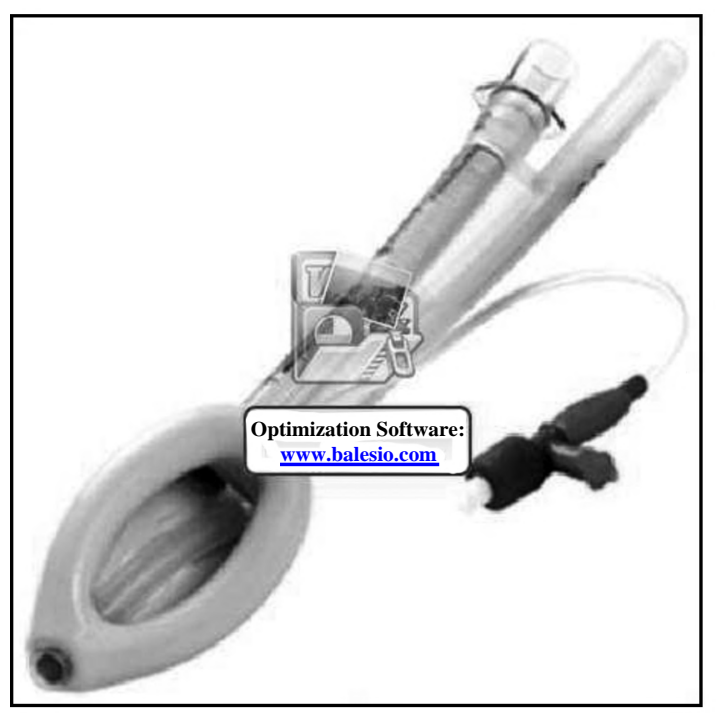

Fig. (8): LMA ProSeal.

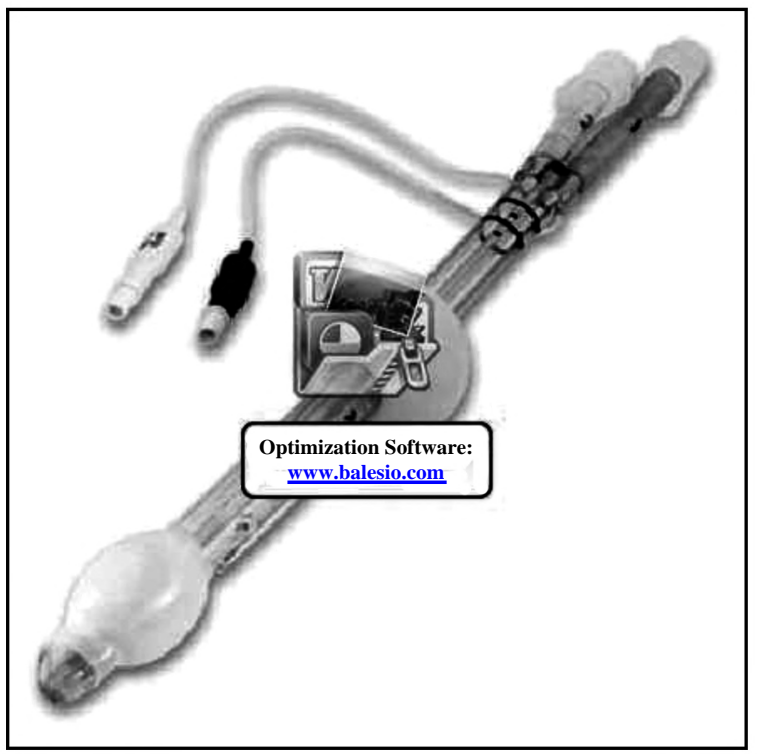

Fig. (5): Combitube.

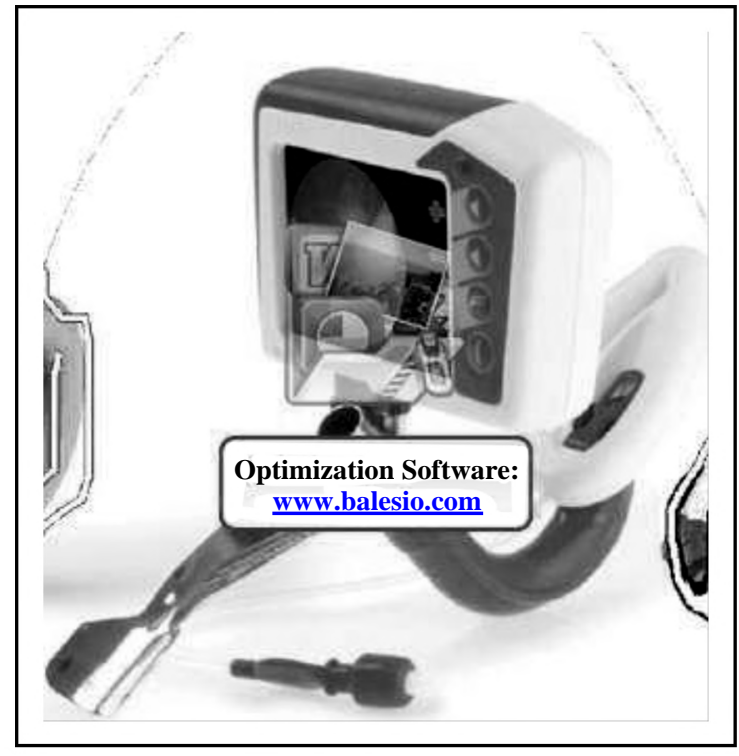

Fig. (7): The LMA-CTrach.

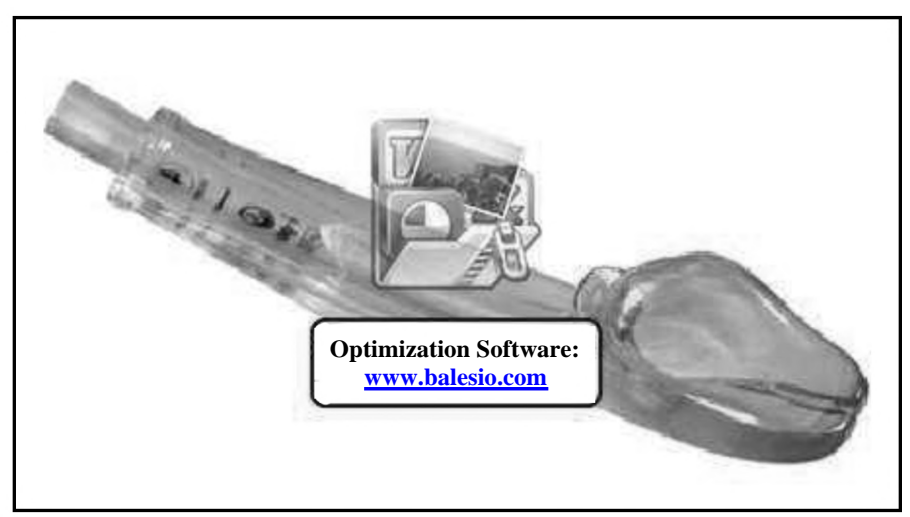

Fig. (9): I-Gel. 


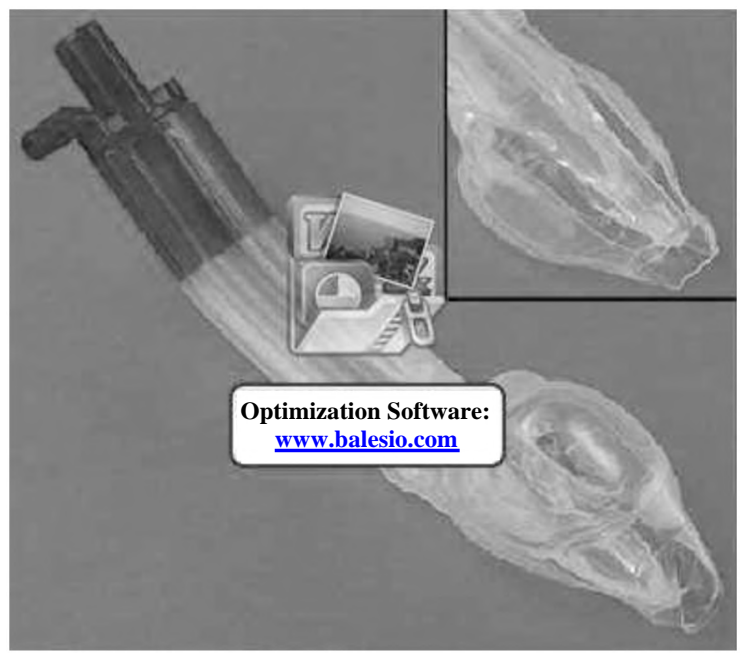

Fig. (10): Baska mask.

\section{Contraindications of LMA:}

The primary contraindication to elective use of the LMA is a risk of gastric-contents aspiration (e.g. full stomach, intestinal obstruction, hiatus hernia with significant gastroesophageal reflux, delayed gastric emptying and poor history) [30] .

Others include morbid obesity, bad compliance with the lung or high resistance to airways, glottic or subglottic blockage of the airways, and restricted mouth opening $(<1.5 \mathrm{~cm})$. CLMA has a record of safety with only one direct loss in an approximately 200 million uses [31].

\section{Indications of LMA: [31]:}

- The SGD has been used for a wide variety of procedures, but it is probably best suited to short cases, making it especially useful for outpatient surgery.

- For patients with difficult face mask ventilation.

- For patients with difficult or failed intubation.

- The SGD can be used in pediatric, including small infants particularly with children in whom unusual anatomy makes tracheal intubation difficult.

- Remote anesthesia: Including diagnostic imaging and radiotherapy procedures, can often be managed by using SGD.

- Supplementing regional block when patients become restless and cannot tolerate prolonged surgery under regional anesthesia.

- Resuscitation: Successful use of the SGD during cardiac arrest has been reported.

- Out-of-hospital use: Including air transfers.
- Obstetrics: Because the risk of aspiration of gastric contents is high in the obstetrical patient, the use of an SGD is usually not recommended however, it has been used in healthy parturients for elective cesarean section if intubation or ventilation cannot be performed, the SGD may be Lifesaving.

- Professional singers: The SGD causes less change in vocal function.

\section{Complications of SGD:}

- Aspiration of gastric contents:

The SGD does not form a tight seal around the larynx and cannot be relied on to protect the tracheo bronchial tree from the contents of the gastrointestinal tract as reliably as can a tracheal tube, the incidence of aspiration can be reduced by limiting the elective use of the SGD to fasting patients who are not at increased risk for gastro esophageal reflux. Gastric distention can be minimized by using the correct size mask, avoiding under-or over inflating the cuff, careful positioning and fixation, maintaining adequate anesthetic depth and relaxation throughout surgery, and low inflation pressures. The use of low tidal volumes and low inspiratory flow rates will help to keep peak airway pressure low. The mean pressure at which gastric insufflation occurs is about $28 \mathrm{~cm} \mathrm{H} 2 \mathrm{O}$ [32].

\section{Gastric distention:}

Gastric distention, which has been implicated as a factor in aspiration, can occur with positivepressure ventilation. The incidence of gastric distention increases with increasing airway pressure and tidal volume but is unlikely to occur at airway pressures of less than $20 \mathrm{~cm} \mathrm{H} 2 \mathrm{O}(30 \mathrm{~cm} \mathrm{H} 2 \mathrm{O}$ for the LMA-ProSeal) if the LMA is properly positioned. The use of pressure-limited rather than volume-limited ventilation may help to avoid gastric dilatation [33].

\section{Damage to the device:}

The LMA may break apart. This is usually occurs when the LMA is beyond its useful life span [33]

\section{Traumatic complications:}

Related to local tissue damage and include sore throat, dysphagia, and dysarthria. The SGD may cause transient changes in vocal cord function. This complication was possibly related to cuff over inflation [10].

\section{Conclusion:}

Sometimes there is a difficult situation that can face the anesthologist which is cannot intubate 
cannot ventilate which is very dangerous and can lead to death. The introduction of the supraglottic airway devices is considered a solution to this problem which help not only to maintain ventilation but also can be a tunnel that facilitate the tracheal intubation Supraglottic Airway Devices are devices that ventilate patients by delivering anesthetic gases/oxygen above the level of the vocal cords and are designed to overcome the disadvantages of endotracheal intubation. As: Soft tissue, tooth, vocal cords, laryngeal and tracheal damage, exaggerated hemodynamic response, barotrauma, etc. The advantages of the Supraglottic airway devices include: Avoidance of laryngoscopy, less invasive for the respiratory tract, better tolerated by patients, increased ease of placement, improved hemodynamic stability in emergence, less coughing, less sore throat, hands free airway and easier placement by inexperienced personal The American Society of Anesthesiologists' Task Force on Management of the Difficult Airway suggests considering the use of the Supraglottic airway devices when intubation problems occur in patients with a previously unrecognized difficult airway, especially in a "cannot ventilate, cannot intubate" situation.

\section{References}

1- MICHALEK P., DONALDSON W., VOBRUBOVA E. and HAKL M.: Complications associated with the use of supraglottic airway devices in perioperative medicine. BioMed. Research International, 2015, 2015.

2- COOK T. and HOWES B.: Supraglottic airway devices: Recent ad vances. Continuing Education in Anaesthesia, Critical Care and Pain, Apr. 1, 11 (2): 56-61, 2011.

3- MICHÁLEK P. and MILLER D.M.: Airway management evolution-in a search for an ideal extraglottic airway device. Prague Med. Rep., 115 (3-4): 87-103, 2014.

4- RAMACHANDRAN S.K. and KUMAR A.M.: Supraglottic Airway DevicesDiscussion. Respiratory care, Jun. 1; 59 (6): 920-32, 2014.

5- POLAT R., AYDIN G.B., ERGIL J., SAYIN M., KOKULU T. and ÖZTÜRK I.: Comparison of the i-gelTM and the Laryngeal Mask Airway ClassicTM in terms of clinical performance. Revista brasileira de anestesiologia, Oct., 65 (5): 343-8, 2015.

6- HIRSCH N.P., SMITH G.B. and HIRSCH P.O.: Alfred Kirstein: Pioneer of direct laryngoscopy. Anaesthesia, Jan., 41 (1): 42-5, 1986.

7- LEECH B.C.: The Pharyngeal Bulb Gasway: A New Aid in Cyclopropane Anesthesia. Anesthesia \& Analgesia, Jan. 1, 16 (1): 22-5, 1937.

8- HARIDAS R.P.: The leech airway or pharyngeal bulb gasway. Anaesth Intensive Care, 39 (Suppl 1): 5-10.

9- BRAIN A.: The laryngeal mask-a new concept in airway management. BJA: British Journal of Anaesthesia, Aug. 1; 55 (8): 801-6, 1983.
10- MILLER D.M.: A proposed classification and scoring system for supraglottic sealing airways: A brief review. Anesthesia \& Analgesia, Nov. 1, 99 (5): 1553-9, 2004.

11- COOK T.M., WOODALL N. and FRERK C.: Fourth National Audit Project. Major complications of airway management in the UK: Results of the Fourth National Audit Project of the Royal College of Anaesthetists and the Difficult Airway Society. Part 1: Anaesthesia. British Journal of Anaesthesia, Mar. 29, 106 (5): 617-31, 2011.

12- BASKETT P.J.: The laryngeal mask in resuscitation. Resuscitation, Oct. 1, 28 (2): 93-5, 1994.

13- PENNANT J.H. and WHITE P.F.: The laryngeal mask airway. Its uses in anesthesiology. Anesthesiology, Jul., 79 (1): 144-63, 1993.

14- BRIMACOMBE J.: The advantages of the LMA over the tracheal tube or facemask: A meta-analysis. Canadian Journal of Anaesthesia, Nov. 1, 42 (11): 1017-23, 1995.

15- WEINSTEIN R.A., RUTALA W.A. and WEBER D.J.: Creutzfeldt-Jakob disease: Recommendations for disinfection and sterilization. Clinical Infectious Diseases, May 1, 32 (9): 1348-56, 2001.

16- LOPEZ GIL M., BRIMACOMBE J. and ALVAREZ M. Safety and efficacy of the laryngeal mask airway A prospective survey of 1400 children. Anaesthesia, Oct., 51 (10): 969-72, 1996.

17- ASAI T., NAGATA A. and SHINGU K.: Awake tracheal intubation through the laryngeal mask in neonates with upper airway obstruction. Pediatric Anesthesia, Jan., 18 (1): 77-80, 2008.

18- TREVISANUTO D., FERRARESE P., ZANARDO V. and CHIANDETTI L.: Laryngeal mask airway in neonatal resuscitation: A survey of current practice and perceived role by anaesthesiologists and paediatricians. Resuscitation, Mar 1, 60 (3): 291-6, 2004.

19-ZANARDO V., WEINER G., MICAGLIO M., DOGLIONI N., BUZZACCHERO R. and TREVISANUTO D.: Delivery room resuscitation of near-term infants: Role of the laryngeal mask airway. Resuscitation, Mar. 1, 81 (3): 327 30, 2010.

20- CHOO C.Y., KOAY C.K. and YOONG C. S.: A randomised controlled trial comparing two insertion techniques for the Laryngeal Mask Airway FlexibleTM in patients undergoing dental surgery. Anaesthesia, Sep., 67 (9): 986-90, 2012.

21- SAEEDI M., HAJISEYEDJAVADI H., SEYEDHOSSEINI J., ESLAMI V. and SHEIKHMOTAHARVAHEDI H. Comparison of endotracheal intubation, combitube, and laryngeal mask airway between inexperienced and experienced emergency medical staff: A manikin study. International journal of critical illness and injury science, Oct., 4 (4): 303, 2014.

22- KAPOOR S., JETHAVA D.D., GUPTA P., JETHAVA D. and KUMAR A.: Comparison of supraglottic devices i-gel ${ }^{\circledR}$ and LMA Fastrach $®$ as conduit for endotracheal intubation. Indian Journal of Anaesthesia, Jul., 58 (4): 397,2014 
23- TIMMERMANN A.: Supraglottic airways in difficult airway management: Successes, failures, use and misuse. Anaesthesia, Dec., 66: 45-56, 2011.

24- LIU E.H., GOY R.W. and CHEN F.G.: The LMA CTrachTM, a new laryngeal mask airway for endotracheal intubation under vision: evaluation in 100 patients. British journal of anaesthesia, Jan. 16, 96 (3): 396-400, 2006.

25- APFELBAUM J.L., HAGBERG C.A., CAPLAN R.A., BLITT C.D., CONNIS R.T., NICKINOVICH D.G., et al.: Practice guidelines for management of the difficult airwayan updated report by the American Society of Anesthesiologists task force on management of the difficult airway. Anesthesiology: The Journal of the American Society of Anesthesiologists, 118 (2): pp. 251-70, 2013.

26- ALMEIDA G., COSTA A.C. and MACHADO H.S.: Supraglottic airway devices: A review in a new era of airway management. J. Anesth. Clin. Res., 7 (647): 2, 2016.

27- WONG D.T., YANG J.J., MAK H.Y. and JAGANNATHAN N.: Use of intubation introducers through a supraglottic airway to facilitate tracheal intubation: A brief review. Canadian Journal of Anesthesia/Journal canadien d'anesthésie, Jul. 1, 59 (7): 704-15, 212.

28- POURNAJAFIAN A., ALIMIAN M., ROKHTABNAK F., GHODRATY M. and MOJRI M.: Success rate of airway devices insertion: Laryngeal mask airway versus supraglottic gel device. Anesthesiology and Pain medicine, Apr., 5 (2), 2015.

29- ALEXIEV V., OCHANA A., ABDELRAHMAN D., COYNE J., McDONNELL J.G., O'TOOLE D.P., et al.: Comparison of the Baska ${ }^{\circledR}$ mask with the single-use laryngeal mask airway in low-risk female patients undergoing ambulatory surgery. Anaesthesia, Oct., 68 (10): 1026-32, 2013.

30- BRIMACOMBE J.R. and BERRY A.: Active swallowing to aid LMA insertion in awake patients. Anesthesia \& Analgesia, May 1, 78 (5): 1029, 1994.

31- BENUMOF J.L.: Laryngeal mask airway. Indications and contraindications. Anesthesiology, Nov., 77 (5): 843, 1992.

32- SMITH C.: Rapid-sequence intubation in adults: Indications and concerns. Clinical Pulmonary Medicine, 1; 8 (3): 147-65, 2001.

33- SIKER D. and GRIMALDOS J.P.: Volume controlled ventilation in children with a laryngeal mask airway causes an air filled esophagus: Pressure limited ventilation avoids this problem. Inanesthesia and Analgesia, Feb. 1 (Vol. 90, No. 2, pp. U223-U223). 530 WALNUT ST, PHILADELPHIA, PA 19106-3621 USA: Lippincott Williams \& Wilkins, 2000.

\section{آجهزة ممرات الهواء فوق الحنجرة، نظرة عامة}

$$
\begin{aligned}
& \text { المحافظة على مجرى الهواء للمريض واحدة من آهم مسئوليات طبيب التخدير لآن صعوية تركيب الآنبوية الحنجرية مسئولة عن نسبة كبيرة }
\end{aligned}
$$

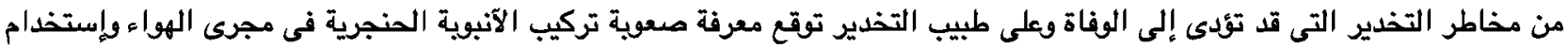

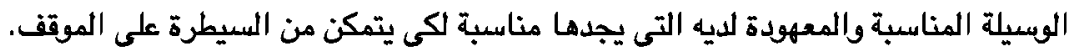

$$
\begin{aligned}
& \text { وجد آنه من آخطر المواقف التى تواجه طبيب التخدير آنه فى بعض الآحيان لا يواجه هعوبة في تركيب الآنبوية الحنجرية فحسب ولكن }
\end{aligned}
$$

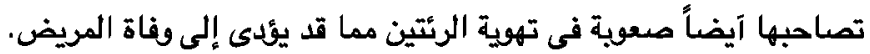

$$
\begin{aligned}
& \text { ومن هنا فإن إختراع الآجهزة الهوائية فوق الهنجرة تعد من آهم الحلول ليس فقط فى تهوية الرئتين فى حالة علم القدرة على تركيب الآنبوبة } \\
& \text { الحنجرية ولكن آيضاً هنال آنواع منها تستخلم في تركيب الآنبوبة الصنجرية. }
\end{aligned}
$$

